\title{
Management of Chronic Obstructive Pulmonary Disease in Patients Admitted to a Tertiary Care Centre for Exacerbation of Their Disease
}

\author{
Roxanne Dault, Anne-Isabelle Dubé, Lucie Blais, Robert Boileau, Pierre Larrivée, Mario-Eddy Dumas, \\ and Marie-France Beauchesne
}

\begin{abstract}
Background: Acute exacerbation of chronic obstructive pulmonary disease (COPD) is associated with an accelerated decline in lung function and a significant decrease in health status. Maintenance therapy with respiratory medications can reduce the risk of such exacerbations.

Objective: To determine whether respiratory maintenance medications were being prescribed in accordance with the 2007 COPD guidelines of the Canadian Thoracic Society for patients admitted to hospital for acute exacerbation of COPD.
\end{abstract}

Methods: A chart review was conducted for admissions to the Centre hospitalier universitaire de Sherbrooke, in Sherbrooke, Quebec, for acute exacerbation of COPD (according to diagnostic codes in the International Statistical Classification of Diseases and Related Health Problems, 10th revision) between January 1, 2008, and January 31, 2011. Data were extracted from patients' medical charts concerning respiratory medications prescribed before the admission, during the hospital stay, and at discharge.

Results: A total of 846 hospital admissions involving 561 patients were reviewed. In almost $70 \%$ of admissions for which data were available on respiratory medications prescribed before the admission, during the hospital stay, and at discharge (238/341 [69.8\%]), a combination of 3 medications was prescribed at discharge: tiotropium, a long-acting $\beta_{2}$ agonist, and an inhaled corticosteroid. For more than $80 \%$ of the admissions, a prescription for at least one inhaled long-acting bronchodilator was documented both on admission and at discharge. Few patients had a prescription for inhaled corticosteroid without long-acting $\beta_{2}$ agonist, but the number of admissions with a prescription for regular use of systemic corticosteroids increased at discharge.

Conclusions: Respiratory medications were generally prescribed in accordance with Canadian COPD guidelines, but improvements could be made regarding use of the combination of tiotropium, long-acting $\beta_{2}$ agonist, and inhaled corticosteroid, as well as long-term use of systemic corticosteroids.

Key words: acute exacerbation of chronic obstructive pulmonary disease, Canadian COPD guidelines, hospital admission

\section{RÉSUMÉ}

Contexte : L'exacerbation aiguë de la maladie pulmonaire obstructive chronique (MPOC) est associée à une réduction accélérée de la fonction pulmonaire et à un déclin notable de l'état de santé. Les médicaments respiratoires d'entretien peuvent réduire le risque d'une telle exacerbation.

Objectif : Déterminer si les médicaments respiratoires d'entretien ont été prescrits conformément aux lignes directrices de 2007 de la Société canadienne de thoracologie pour la prise en charge de la MPOC chez les patients hospitalisés pour une exacerbation aiguë de la MPOC.

Méthodes : Une analyse rétrospective des dossiers médicaux des patients hospitalisés au Centre hospitalier universitaire de Sherbrooke, à Sherbrooke (Québec), pour une exacerbation aiguë de la MPOC (d'après les codes diagnostiques de la Classification statistique internationale des maladies et des problèmes de santé connexes, $10^{\mathrm{c}}$ révision) entre le $1^{\mathrm{er}}$ janvier 2008 et le 31 janvier 2011 a été menée. Les renseignements sur les médicaments respiratoires qui ont été prescrits avant et pendant l'hospitalisation et au congé ont été extraits des dossiers médicaux des patients.

Résultats : Un total de 846 admissions à l'hôpital intéressant 561 patients ont fait l'objet de l'analyse. Dans presque $70 \%$ des admissions pour lesquelles on disposait des renseignements sur les médicaments respiratoires prescrits avant et pendant l'hospitalisation et au congé (238/341 [69,8\%]), une combinaison de trois médicaments a été prescrite au congé : le tiotropium, un $\beta_{2}$-agoniste à action prolongée et un corticostéroïde en inhalation. Dans plus de $80 \%$ des admissions, une ordonnance pour au moins un bronchodilatateur à action prolongée a été consignée à l'admission et au congé. Peu de patients avaient reçu une ordonnance pour un corticostéroïde en inhalation sans un $\beta_{2}$-agoniste à action prolongée, mais le nombre d'admissions pourvues d'une ordonnance pour un corticostéroïde systémique était plus élevé lors du congé.

Conclusions : Les médicaments respiratoires ont été généralement prescrits conformément aux lignes directrices canadiennes pour la prise en charge de la MPOC, mais des améliorations pourraient être apportées concernant l'emploi du traitement associant le tiotropium, un $\beta_{2}$-agoniste à action prolongée et un corticostéroïde en inhalation, et l'utilisation à long terme d'un corticostéroïde systémique.

Mots clés : exacerbation aiguë de la maladie pulmonaire obstructive chronique, lignes directrices canadiennes pour la prise en charge de la MPOC, admission à l'hôpital 


\section{INTRODUCTION}

Chronic obstructive pulmonary disease (COPD) is the fourth leading cause of death in Canada and is associated with one of the highest rates of hospital admission. ${ }^{1,2} \mathrm{~A}$ previous study ${ }^{3}$ showed that only $34 \%$ of patients with COPD recruited in the primary care setting were receiving pharmacological treatments as recommended by the 2003 COPD guidelines of the Canadian Thoracic Society. A study conducted in the United States demonstrated that 66\% of COPD patients received recommended treatments, but that study was limited to in-hospital management of acute exacerbation of COPD (AECOPD). ${ }^{4}$ To the authors' knowledge, no study describing maintenance respiratory medications prescribed to patients admitted to hospital for AECOPD has been conducted in Canada. The main purpose of the current study was to estimate the proportion of admissions for AECOPD at the Centre hospitalier universitaire de Sherbrooke (a tertiary care centre in Sherbrooke, Quebec) with prescriptions for maintenance respiratory medications in accordance with the 2007 guidelines of the Canadian Thoracic Society for management of COPD. The study also aimed to briefly describe in-hospital management of this condition.

\section{METHODS}

The primary objective of this study was to determine the proportion of admissions for AECOPD for which the combination of tiotropium plus a long-acting $\beta_{2}$ agonist $\left(\mathrm{LAB}_{2} \mathrm{~A}\right)$ and an inhaled corticosteroid was prescribed at discharge. This combination is recommended by the most recent Canadian COPD guidelines ${ }^{1}$ for patients with moderate to severe COPD and a history of exacerbation (one or more exacerbations per year, on average, for 2 consecutive years), to reduce the frequency and severity of exacerbations, and it has been shown to reduce the risk of admission to hospital for AECOPD. ${ }^{5}$ The Global Initiative for Chronic Obstructive Lung Disease $(\mathrm{GOLD})^{6}$ also recommends this combination (as second-line therapy) for patients with COPD who are at high risk of exacerbation. The secondary objectives of this study were (1) to describe maintenance respiratory medications prescribed before, during, and after a hospital stay for AECOPD and (2) to describe in-hospital management of AECOPD, more specifically for patients treated with systemic corticosteroids and respiratory antibiotics.

\section{Study Design}

In this descriptive study, medical charts were reviewed for patients who were admitted to the study hospital for AECOPD between January 1, 2008, and January 31, 2011. This period was chosen to allow for integration of the 2007 COPD guidelines into practice and to ensure availability of complete data for the last patient whose records could be retrieved by the medical archivist during the period available for data collection. This study was approved by the institution's research ethics committee (the Comité d'éthique de la recherche en santé chez l'humain).

Hospital admissions for AECOPD were identified by the medical archivist, according to the admission diagnosis documented on discharge summaries, which were based on codes in the International Statistical Classification of Diseases and Related Health Problems, 10th revision (ICD-10).

\section{Data Collection}

At the study institution, both computerized and paperbased medical charts were available for every patient admitted during the study period. The medical information captured in the computerized chart can be extracted from a clinical data warehouse (the Centre informatisé de recherche évaluative en service et soins de santé). The medical information written in the medical chart must be collected manually by reviewing each individual chart. Both methods of data extraction were used in this study.

The following data were extracted from the clinical data warehouse: age, sex, body mass index, the medical department from which the patient was discharged, whether the patient was discharged to home or not, length of the hospital stay, health care use (previous emergency room visits or hospital admissions for AECOPD in the 12 months before the current admission), death from any cause during hospital stay, prescriptions for systemic corticosteroids, prescriptions for a respiratory antibiotic (second- or third-generation cephalosporin, respiratory quinolone, second- or third-generation macrolide, B-lactam/ ß-lactamase inhibitor), and prescriptions for maintenance respiratory medications $\left(\mathrm{LAB}_{2} \mathrm{~A}\right.$, long-acting anticholinergic [LAAC], inhaled corticosteroid, theophylline) during the hospital admission for AECOPD.

Individual medical charts were reviewed to retrieve the following data: percent predicted forced expiratory volume in 1 second $\left(\mathrm{FEV}_{1}\right)$, ratio of $\mathrm{FEV}$, to forced vital capacity (FVC), the occurrence of any outpatient visits with a respiratory physician in the past, and maintenance respiratory medications prescribed before admission and at discharge.

Disease severity was estimated from the percent predicted $\mathrm{FEV}_{1}$, based on the classification described in the $2007 \mathrm{COPD}$ guidelines. ${ }^{1}$ Results of respiratory function tests performed before the admission (and, if more than one set of results was available, using results closest to the date of the admission) were selected for analysis; alternatively, if no results were available from testing performed before admission, respiratory function tests documented during the hospital stay were used.

Information about respiratory medications prescribed before and after the hospital stay was retrieved from the 
medical charts when the form used for medication reconciliation was available. This form, which is initially completed by a pharmacy technician or pharmacist upon admission, contains information about medications used by the patient before the admission. The form is also used at discharge by the physician for prescribing medications to be used after discharge.

\section{Outcomes}

The main outcome in this study was the proportion of hospital admissions for which the guideline-recommended combination of tiotropium, a $\mathrm{LAB}_{2} \mathrm{~A}$, and an inhaled corticosteroid was prescribed at discharge. The following secondary outcomes were also assessed: proportion of admissions with at least one inhaled long-acting bronchodilator prescribed (before admission, in hospital, and at discharge); proportion of admissions with a prescription for inhaled corticosteroid combined with a $\mathrm{LAB}_{2} \mathrm{~A}$ (before admission, in hospital, and at discharge); proportion of admissions with a prescription for regular use of a systemic corticosteroid (i.e., at least 30 consecutive days, before admission and at discharge); proportion of admissions with a prescription for systemic corticosteroid for in-hospital management of AECOPD; and proportion of admissions with a prescription for a respiratory antibiotic for in-hospital management of AECOPD.

The Canadian COPD guidelines ${ }^{1}$ recommend the following: use of inhaled long-acting bronchodilators, to improve quality of life and reduce the risk of COPD exacerbations; prescription of inhaled corticosteroid in combination with $\mathrm{LAB}_{2} \mathrm{~A}$ (i.e., the corticosteroid should be combined with a $\mathrm{LAB}_{2} \mathrm{~A}$ and should not be used as monotherapy); and avoidance of long-term use of systemic corticosteroids. The GOLD guidelines $^{6}$ make similar recommendations, suggesting the use of long-acting bronchodilators to reduce the risk of exacerbation. They also indicate that inhaled corticosteroid monotherapy (i.e., without long-acting bronchodilators) is not recommended (the guidelines suggest that these drugs may be used with tiotropium but state that this recommendation is not evidence-based) and that long-term monotherapy with oral corticosteroids is not recommended. Both the Canadian and the international COPD guidelines recommend the use of systemic corticosteroids for in-hospital management of AECOPD and antibiotics for purulent exacerbations. ${ }^{1,6}$

\section{Statistical Analysis}

The unit of analysis was hospital admission for AECOPD. As such, an individual patient could contribute data for more than one hospital admission during the study period. Descriptive results are presented as proportions, medians, or means and standard deviations, as appropriate. Data were analyzed with the Microsoft Office Excel 2007 software application.

\section{RESULTS}

\section{Baseline Characteristics}

A total of 846 admissions, involving 561 patients, were analyzed. Baseline characteristics are presented in Table 1. Discharge summaries were completed mainly by the departments of respiratory medicine, family medicine, and internal medicine. Respiratory function test results were available for $688(81.3 \%)$ of the admissions (with testing for 70 admissions [8.3\% of the total] being done during the hospital stay), and in almost all cases, the results suggested moderate to very severe disease (Table 1). Overall, death occurred for 37 (4.4\%) of the admissions.

\section{Maintenance Respiratory Medications Prescribed Before Admission and at Discharge}

Information on medications prescribed before and after the hospital stay was available for 341 (40.3\%) of the cases. The combination of tiotropium, a $\mathrm{LAB}_{2} \mathrm{~A}$, and an inhaled corticosteroid was the most frequently prescribed therapy before and after the patient's hospital stay (Table 2). For most of these 341 admissions, at least one inhaled long-acting bronchodilator (LAB $\mathrm{A}_{2}$ and/or LAAC) was prescribed before (284 [83.3\%]) and after (321 [94.1\%]) the hospital stay. A small proportion of patients had a prescription for inhaled corticosteroid not combined with a $\mathrm{LAB}_{2} \mathrm{~A}$ before and after the hospital stay (Table 2). Few patients received oral corticosteroids on a regular basis (i.e., for more than 30 consecutive days, excluding prolonged taper) before admission (44 [12.9\%]), but the proportion increased at discharge $(57$ [16.7\%]). Theophylline was prescribed in about $7 \%$ of the admissions (24 [7.0\%] before and 26 [7.6\%] after the hospital stay).

\section{In-hospital Management}

Most exacerbations were treated with systemic corticosteroids (Table 3). A respiratory antibiotic was prescribed in about $63 \%$ of the admissions, and moxifloxacin was used in the majority of these cases. The most common maintenance respiratory medication regimen prescribed was the combination of tiotropium- $\mathrm{LAB}_{2} \mathrm{~A}$-inhaled corticosteroid.

\section{DISCUSSION}

The proportion of hospital admissions for which the combination tiotropium-LAB $\mathrm{A}$-inhaled corticosteroid was prescribed at discharge was high (about 70\%), and there was an absolute increase of $14 \%$ between admission and discharge. In most cases, recommended maintenance respiratory medications were prescribed.

The combination of tiotropium, $\mathrm{LAB}_{2} \mathrm{~A}$, and inhaled corticosteroid is beneficial in reducing the risk of admission to 
Table 1. Baseline Characteristics of Admissions for Acute Exacerbation of Chronic Obstructive Pulmonary Disease (COPD)

\begin{tabular}{|c|c|}
\hline Characteristic & $\begin{array}{l}\text { No. (\%) of Admissions* } \\
\qquad(n=846) \dagger\end{array}$ \\
\hline \multicolumn{2}{|l|}{ Demographic } \\
\hline Age, mean \pm SD (years) & $71.5 \pm 11.1$ \\
\hline Sex, no. (\%) male & $401(47.4)$ \\
\hline \multicolumn{2}{|l|}{ Clinical } \\
\hline BMI $\left(\mathrm{kg} / \mathrm{m}^{2}\right)$, mean $\pm \mathrm{SD}(n=533) \neq$ & $28.0 \pm 9.2$ \\
\hline Mean \% predicted FEV \pm SD $(n=622) \S$ & $41.5 \pm 16.1$ \\
\hline \multicolumn{2}{|l|}{ Disease severity, based on FEV $(n=622) \S$} \\
\hline Mild $\left(F E V_{1} \geq 80 \%\right)$ & $14 \quad(2.3)$ \\
\hline Moderate (FEV $\geq 50$ and < 80\%) & $160(25.7)$ \\
\hline Severe $(\mathrm{FEV}, \geq 30$ and $<50 \%)$ & $299(48.1)$ \\
\hline Very severe $(\mathrm{FEV},<30 \%)$ & $149(24.0)$ \\
\hline \multicolumn{2}{|l|}{ Unit of dischargeף } \\
\hline Respirology & $309(36.5)$ \\
\hline Family medicine & $300(35.5)$ \\
\hline Internal medicine & $196(23.2)$ \\
\hline Other & $41 \quad(4.8)$ \\
\hline \multicolumn{2}{|l|}{ Clinical and hospital history } \\
\hline At least one previous outpatient visit with a respirologist & $454(53.7)$ \\
\hline Discharged home after hospital stay & $590(69.7)$ \\
\hline $\begin{array}{l}\text { Mean no. of admissions for acute exacerbation of } \\
\text { COPD in previous year per patient }\end{array}$ & 0.93 \\
\hline $\begin{array}{l}\text { Mean no. of emergency visits for acute exacerbation } \\
\text { of COPD in previous year per patient }\end{array}$ & 0.42 \\
\hline Median no. of days in hospital (current visit) & 5.0 \\
\hline No. (\%) deaths from any cause during hospital stay & $37 \quad(4.4)$ \\
\hline \multicolumn{2}{|c|}{ 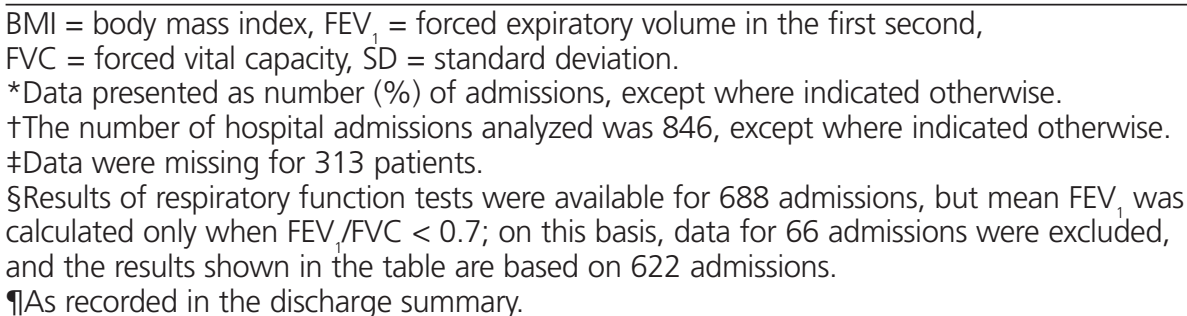 } \\
\hline
\end{tabular}

\section{Table 2. Respiratory Medications Prescribed before Admission to Hospital and at Discharge}

\begin{tabular}{lrrrr} 
& \multicolumn{3}{c}{ No. (\%) of Admissions Analyzed } \\
& \multicolumn{4}{c}{$(\boldsymbol{n}=\mathbf{3 4 1})$} \\
\cline { 2 - 5 } Medications & \multicolumn{3}{c}{ Before Admission } & At Discharge \\
\hline LAAC + LAB ${ }_{2} A+I C S$ & 191 & $(56.0)$ & 238 & $(69.8)$ \\
LAB ${ }_{2} A+I C S$ & 49 & $(14.4)$ & 37 & $(10.9)$ \\
LAB ${ }_{2} A+L A A C$ & 19 & $(5.6)$ & 12 & $(3.5)$ \\
LAAC monotherapy & 17 & $(5.0)$ & 24 & $(7.0)$ \\
ICS monotherapy & 14 & $(4.1)$ & 7 & $(2.1)$ \\
LAAC + ICS & 7 & $(2.1)$ & 8 & $(2.3)$ \\
LAB ${ }_{2} A$ monotherapy & 1 & $(0.3)$ & 2 & $(0.6)$ \\
Short-acting bronchodilators only & 43 & $(12.6)$ & 13 & $(3.8)$ \\
\hline
\end{tabular}

ICS = inhaled corticosteroids, LAAC = long-acting anticholinergics, LAB $\mathrm{A}_{2}=$ long-acting

$\beta_{2}$-agonists. 
Table 3. In-Hospital Management of Acute Exacerbation of Chronic Obstructive Pulmonary Disease

\begin{tabular}{|c|c|}
\hline Prescribed Pharmacologic Treatments & No. $(\%)$ of Admissions $(n=846)$ \\
\hline \multicolumn{2}{|l|}{ Corticosteroids } \\
\hline Methylprednisolone and/or prednisone & $772(91.3)$ \\
\hline Methylprednisolone only & 64 \\
\hline Methylprednisolone and prednisone & 454 \\
\hline Prednisone only & 254 \\
\hline \multicolumn{2}{|l|}{ Antibiotics } \\
\hline Admissions with $\geq 1$ respiratory antibiotic & $530(62.6)$ \\
\hline Total no. of prescriptions for respiratory antibiotics & 661 \\
\hline Moxifloxacin & 381 \\
\hline Piperacillin-tazobactam & 90 \\
\hline Amoxicillin-clavulanic acid & 90 \\
\hline Ceftriaxone & 40 \\
\hline Azithromycin & 21 \\
\hline Levofloxacin & 15 \\
\hline Amoxicillin & 13 \\
\hline Others* & 11 \\
\hline \multicolumn{2}{|l|}{ Inhaled respiratory medications } \\
\hline$L A A C+L A B_{2} A+I C S$ & $484(57.2)$ \\
\hline LAAC monotherapy & $84(9.9)$ \\
\hline $\mathrm{LAB}_{2} \mathrm{~A}+\mathrm{ICS}$ & $77 \quad(9.1)$ \\
\hline$L A B_{2} A+L A A C$ & $45 \quad(5.3)$ \\
\hline $\begin{array}{l}\text { LAA }{ }^{2} C+\text { ICS } \\
\text { ICS monotherapy }\end{array}$ & $\begin{array}{ll}22 & (2.6) \\
21 & (2.5)\end{array}$ \\
\hline $\mathrm{LAB}_{2} \mathrm{~A}$ monotherapy & $8(0.9)$ \\
\hline Short-acting bronchodilators only & $105(12.4)$ \\
\hline
\end{tabular}

hospital for AECOPD. 5 These agents do not have a specific role in management of an exacerbation, but the GOLD guidelines recommend that long-acting bronchodilators with or without inhaled corticosteroid be prescribed in hospital, before discharge. ${ }^{6}$ Although the percentage of exacerbations for which this combination was prescribed was high, there was still room for improvement, considering the consequences associated with hospital admission for AECOPD. ${ }^{1}$ Some might argue that the evidence for the benefits of this combination of medications is limited. In one randomized trial, there was no reduction in the risk of all COPD exacerbations with the combination of tiotropium- $\mathrm{LAB}_{2} \mathrm{~A}$-inhaled corticosteroid, relative to tiotropium alone, but there was a significant reduction in hospital admission rates. ${ }^{5}$

Bronchodilators are currently the mainstay of pharmacological therapy for COPD, ${ }^{1}$ and inhaled long-acting bronchodilators (including tiotropium with or without $\mathrm{LAB}_{2} \mathrm{~A}$ ) were commonly prescribed in the current study. The rate of prescription of these drugs ( $94.1 \%$ at discharge) was higher than that reported in the CAGE study (73\%), but the latter included more patients with mild disease. ${ }^{3}$ Monotherapy with inhaled corticosteroids (i.e., not combined with a $\mathrm{LAB}_{2} \mathrm{~A}$ ) is not recommended by the Canadian Thoracic Society because of the inconsistent benefits of this therapy in $\mathrm{COPD}^{1}$; the proportion of admissions with such a prescription was low in the current study. The COPD guidelines do not recommend regular use of systemic corticosteroids for long-term management of COPD because of the high risk of adverse systemic effects. ${ }^{1}$ In the current study, nearly $15 \%$ of patients had a prescription for regular use of oral corticosteroids before admission, and this rate increased at discharge. We cannot exclude the possibility that it was decided to taper this regimen at a follow-up medical visit; however, at the time of discharge, prescriptions were valid for at least 1 month and any prescriptions suggesting prolonged tapering were excluded. This result suggests that it may be difficult to wean patients with severe disease from this therapy.

In the current study, most patients received a systemic corticosteroid, and just over half had a prescription for a respiratory antibiotic during their hospital stay for AECOPD. The US and New Zealand studies describing in-hospital management of AECOPD reported similar percentages of patients with prescriptions for systemic corticosteroid: $84.9 \%$ and $83 \%$, respectively. ${ }^{4,7}$ However, the rates of antibiotic use were higher $(84.6 \%$ and $80 \%)$ than in the current study, which could be explained by the inclusion of all types of antibiotics in the 
previous analyses. In the current analysis, only respiratory antibiotics were considered, with exclusion of other antibiotics that might be prescribed in the context of AECOPD, such as ciprofloxacin.

When respiratory function tests were available, most results were associated with moderate to severe disease, which is not surprising, given that the risk of exacerbation is related to the severity of the underlying airflow obstruction. ${ }^{1}$ According to the 2007 COPD guidelines, spirometry is required for the diagnosis of COPD and is useful in assessing the severity of airway obstruction. ${ }^{1}$ The results of respiratory function tests performed before or during the hospital stay were documented for $81.3 \%$ of the patients. This rate is much higher than what was reported in a similar study conducted in Europe, in which only $53 \%$ of patients had a respiratory function test documented in their medical chart in the 5 years preceding or the 3 months following hospital admission for AECOPD. ${ }^{8}$ This discrepancy could be explained by the fact that the European study was conducted more than 10 years ago and practice relating to the diagnosis of COPD has improved in recent years.

The median length of stay in this study (5 days) was similar to that reported in a US study ${ }^{4}$ and another conducted in Ontario.' The in-hospital death rate $(4.4 \%)$ was similar to that reported in the US study (4.1\%). ${ }^{4}$

Our study had several limitations. The information was collected retrospectively, and it was impossible to evaluate nonpharmacologic components of COPD management, such as smoking cessation advice or participation in a pulmonary rehabilitation program. Also, information on smoking status, immunization history, comorbidities, patients' ability to use respiratory drug delivery systems correctly, medication adherence, and presence of allergy or drug intolerance was not collected. Furthermore, data regarding maintenance respiratory medications prescribed before and after the hospital stay were available for only $40 \%$ of the admissions. Finally, this study included patients from a single institution, and practice may differ at other sites. The main strength of this study was the analysis of a high number of exacerbations.

This study was descriptive, and it would be interesting to conduct a prospective analysis to more accurately compare pre- and post-exacerbation medications, outcomes in terms of disease severity, predictors of exacerbation, and differences in outcomes in terms of patient management by generalists versus pulmonologists.

\section{CONCLUSIONS}

This study has shown that maintenance respiratory medications were generally prescribed in accordance with the 2007 COPD guidelines of the Canadian Thoracic Society for patients who were admitted to a tertiary care centre in the province of Quebec for AECOPD. However, improvements could be made to achieve higher rates of conformity with the guidelines. Further studies focusing on conformity with nonpharmacologic measures for patients admitted to hospital for AECOPD are required, as several studies have suggested that there is still much work to be done to improve this aspect of COPD care. ${ }^{3,10}$

\section{References}

1. O’Donnell DE, Aaron S, Bourbeau J, Hernandez P, Marciniuk DD, Balter M, et al. Canadian Thoracic Society recommendations for management of chronic obstructive pulmonary disease - 2007 update. Can Respir J 2007;14 Suppl B:5B-32B.

2. Benady S. Le fardeau humain et financier de la MPOC: une des principales causes d'hospitalisation au Canada. Ottawa (ON): Société canadienne de thoracologie; 2010.

3. Bourbeau J, Sedbaldt RJ, Day A, Bouchard J, Kaplan A, Hernandez P, et al. Practice patterns in the management of chronic obstructive pulmonary disease in primary practice: the CAGE study. Can Respir J 2008;15(1): 13-19.

4. Lindenauer PK, Pekow P, Gao S, Crawford AS, Gutierrrez B, Bejamin EM. Quality of care for patients hospitalized for acute exacerbations of chronic obstructive pulmonary disease. Ann Intern Med 2006;144(12):894-903.

5. Aaron SD, Vandemheen KL, Fergusson D, Maltais F, Bourbeau J, Goldstein R, et al.; Canadian Thoracic Society/Canadian Respiratory Clinical Research Consortium. Tiotropium in combination with placebo, salmeterol, or fluticasone-salmeterol for treatment of chronic obstructive pulmonary disease: a randomized trial. Ann Intern Med 2007;146(8): 545-555.

6. Global strategy for the diagnosis, management and prevention of chronic obstructive pulmonary disease. Global Initiative for Chronic Obstructive Lung Disease; [updated 2011; cited 2012 Jun 30]. Available from: www.goldcopd.org

7. Chang CL, Sullivan GD, Karalus NC, Hancox RJ, McLachlan JD, Mills GD. Audit of acute admissions of chronic obstructive pulmonary disease: inpatient management and outcome. Intern Med J 2007;37(4):236-241.

8. Roberts CM, Ryland I, Lowe D, Kelly Y, Bucknall CE, Pearson MG.; Audit Sub-committee of the Standards of Care Committee, British Thoracic Society; Clinical Effectiveness and Evaluation Unit, Royal College of Physicians. Audit of acute admissions of COPD: standards of care and management in the hospital setting. Eur Respir J 2001; 17(3):343-349.

9. Chen Y, Li Q, Johansen H. Age and sex variations in hospital readmissions for COPD associated with overall and cardiac comorbidity. Int J Tuberc Lung Dis 2009;13(3):394-399.

10. Johnston K, Grimmer-Somers K. Pulmonary rehabilitation: overwhelming evidence but lost in translation? Physiother Can 2010;62(4):368-373.

Roxanne Dault is a BSc candidate, Faculté de médecine et des sciences de la santé, Université de Sherbrooke, Sherbrooke, Quebec.

Anne-Isabelle Dubé, PharmD, is an MSc candidate, Faculté de pharmacie, Université de Montréal, Montréal, Quebec.

Lucie Blais, PhD, is a Full Professor, Faculté de pharmacie, Université de Montréal, and a Researcher with the Centre de recherche de I'Hôpital du Sacré-Cœur de Montréal, Montréal, Quebec.

Robert Boileau, MD, is a Respiratory Physician, Centre hospitalier universitaire de Sherbrooke, Sherbrooke, Quebec. 
Pierre Larrivée, MD, is a Respiratory Physician with the Centre hospitalier universitaire de Sherbrooke, a Researcher with the Centre de recherche clinique Étienne-Le Bel, and a Full Professor with the Faculté de médecine et des sciences de la santé, Université de Sherbrooke, Sherbrooke, Quebec.

Mario-Eddy Dumas, MD, is a Pediatrician with the Centre hospitalier universitaire de Sherbrooke, an associate researcher with the Centre de recherche clinique Étienne-Le Bel, and an Associate Professor with the Faculté de médecine et des sciences de la santé, Université de Sherbrooke, Sherbrooke, Quebec.

Marie-France Beauchesne, PharmD, is a Pharmacist with the Centre hospitalier universitaire de Sherbrooke and an Associate Researcher with the Centre de recherche clinique Étienne-Le Bel, Sherbrooke, Quebec. She is also a Clinical Associate Professor, Faculté de pharmacie, Université de Montréal, Montréal, Quebec.

\section{Address correspondence to:}

Marie-France Beauchesne

Faculté de pharmacie

Université de Montréal

CP 6128, succursale centre-ville

Montréal QC H3C 3J7

e-mail: marie-France.beauchesne@umontreal.ca

\section{Acknowledgements}

The authors thank Mendy Malachy, medical archivist at the Centre hospitalier universitaire de Sherbrooke, for her work related to data extraction.

GSK Canada Inc provided an unrestricted grant for this project. The company was not involved in the design and conduct of the study; the collection, management, or interpretation of the data; or the preparation, review, or approval of the manuscript.

\section{CJHP Subscriptions 20I3 / Abonnements au JCPH 2013}

CSHP has introduced both Print and Print + Online pricing models for CJHP subscriptions. Print + Online CJHP is included as a benefit of CSHP membership. All prices are in Canadian funds.

La SCPH a établi une grille tarifaire pour l'abonnement à la copie imprimée du JCPH seulement et pour l'abonnement à la fois aux copies imprimée et électronique du journal. L'abonnement combiné est inclus dans les droits d'adhésion à la SCPH. Tous les prix sont en dollars canadiens.

\begin{tabular}{|l|l|l|}
\hline $\begin{array}{l}\text { Subscriber group / Groupe } \\
\text { d'abonnés }\end{array}$ & $\begin{array}{l}\text { Print only / Texte imprimé } \\
\text { seulement }\end{array}$ & $\begin{array}{l}\text { Print + Online copy } \\
\text { Texte imprimé } \\
\text { et exemplaire électronique }\end{array}$ \\
\hline $\begin{array}{l}\text { Nonmembers within Canada / } \\
\text { Non-membres au Canada }\end{array}$ & $\begin{array}{l}\$ 120.00 \text { per year, plus GST or HST } \\
120,00 \$ \text { par an, plus TPS ou TVH }\end{array}$ & $\begin{array}{l}\$ 160.00 \text { per year, plus GST or HST } \\
160,00 \$ \text { par an, plus TPS ou TVH }\end{array}$ \\
\hline USA / É.-U. & $\begin{array}{l}\$ 150.00 \text { per year } \\
150,00 \$ \text { par an }\end{array}$ & $\begin{array}{l}\$ 190.00 \text { per year } \\
190,00 \text { par an }\end{array}$ \\
\hline Foreign / Étranger & $\$ 190.00$ per year & $\$ 230.00$ per year \\
& $190,00 \$$ par an & 230,00 par an \\
\hline
\end{tabular}

More details can be found at www.cjhp-online.ca. If you would like to purchase a subscription, please fill out our CJHP 2013 Subscription Application Form, which can be found on the CJHP website.

Please direct any comments or questions to Colleen Drake, Publications Administrator, at cdrake@cshp.ca.

Des détails supplémentaires sont fournis à www.cjhp-online.ca. Si vous désirez vous abonner, veuillez remplir le formulaire d'abonnement au JCPH 2013. Vous pouvez l'obtenir en visitant le site Web du JCPH. Pour tout commentaire ou toute question, veuillez vous adresser à Colleen Drake, agente des publications, en écrivant à cdrake@cshp.ca. 